\title{
Total Antioxidant Capacity of Saliva: An Effective Marker of Stress
}

\author{
${ }^{1}$ Maria Ana Karina Erica de Piedade Sequeira, ${ }^{2}$ Zameera Naik
}

\section{ABSTRACT}

Aim: To assess and correlate the level of stress to the total antioxidant capacity of saliva of university exam-going students studying at KLE Vishwanath Katti Institute of Dental Sciences, Belagavi, Karnataka, India, on the day of examination (stressed condition) and in the postexamination period (nonstressed condition).

Materials and methods: Saliva samples of 30 students evaluated by the perceived stress scale on both the day of examination and in the postexamination period were collected and labeled as group I (day of examination) and group II (postexamination period). The total antioxidant capacity was assessed using the spectrophotometric assay based on the molar absorption coefficient of the phosphomolybdenum complex. The correlation between the level of stress and the antioxidant capacity was done using Spearman's correlation test, and the mean values obtained with respect to the two groups were evaluated using Mann-Whitney U test.

Results: The total antioxidant capacity was lower on the day of examination than in the postexamination period $(p=0.001)$. As the stress level increases, the total antioxidant capacity decreases.

Conclusion: Total antioxidant capacity of saliva can serve as an effective marker of stress. Thus, supplementation with antioxidants routinely and especially during periods of stress may be beneficial.

Clinical significance: Present day life is full of targets, necessities, and frustrations. For many people, stress has become a way of life. Stress is not always detrimental. Stress within your comfort zone helps you compete, motivates you, and can even keep you secure. But when stress becomes overwhelming, it damages your well-being, relationships, and quality of life. Thus, managing and diagnosing stress is important.

Keywords: Nutrition, Oral systemic diseases, Oxidative stress, Salivary diagnostics.

How to cite this article: de Piedade Sequeira MAKE, Naik Z. Total Antioxidant Capacity of Saliva: An Effective Marker of Stress. J Contemp Dent 2017;7(1):12-16.

Source of support: Nil

Conflict of interest: None

\footnotetext{
${ }^{1}$ Student, ${ }^{2}$ Professor

${ }^{1,2}$ Department of Oral Medicine and Radiology, KLE Vishwanath Katti Institute of Dental Sciences, KLE University, Belagavi Karnataka, India

Corresponding Author: Maria Ana Karina Erica de Piedade Sequeira, Student, Department of Oral Medicine and Radiology KLE Vishwanath Katti Institute of Dental Sciences, KLE University Belagavi, Karnataka, India, Phone: +919164405196 e-mail: anaseq11@gmail.com
}

\section{INTRODUCTION}

The term "stress," as it is currently used, was coined by Hans Selye in 1936, who defined it as "the nonspecific response of the body to any demand for change." Actually, "everybody knows what stress is, and nobody knows what it is," once noted and conveyed by Selye ${ }^{1}$ as the vagueness of the word "stress." Well, based on present knowledge, we can define stress as a chemical, emotional, or physical factor that causes detrimental effects on the body, which manifests with disease. Basically, stress is anything that disrupts your natural poise.

Free radicals are atoms with an odd, unpaired electron. These are very unstable and react with other compounds, trying to capture the needed electron to gain stability. When the "attacked" molecule loses its electron, it becomes a free radical itself, beginning a chain reaction. Once the process is started, it proceeds as a cascade, finally resulting in the disruption of a living cell. Antioxidants neutralize free radicals by donating one of their own electrons, ending the electron-"stealing" reaction. The antioxidant nutrients themselves do not become free radicals because they are stable in either form. They act as scavengers, helping to prevent cell and tissue damage that could lead to disease. ${ }^{2}$

At a more biochemical level, oxidative phosphorylation takes place in the mitochondria and is a major source of adenosine triphosphate in aerobic organisms. As a by-product, it produces free radicals, including reactive oxygen species (ROS), reactive nitrogen species (RNS), and carbon-centered and sulfur-centered radicals. ${ }^{3}$ The primary ROS generated are hydrogen peroxide $\left(\mathrm{H}_{2} \mathrm{O}_{2}\right)$, superoxide radical $\left(\mathrm{O}_{2}^{-}\right)$, and hydroxyl radical $\left[\mathrm{OH}^{-}\right]$. The RNS mainly includes nitric oxide and nitrogen dioxide. The free radical/antioxidant balance is critical. When this balance is disturbed, oxidative and nitrosative stress is initiated as a result of overproduction of ROS and/or insufficiency of the antioxidant defense mechanisms. ${ }^{4,5}$ As a consequence to this oxidative stress, damage to cells and organs with impairment of their function can occur.

A study found that $2.7 \%$ of Swedish medical students had committed suicide. ${ }^{6}$ Another study conducted in UAE among medical students, trainees, and university faculty using a questionnaire showed $65 \%$ of the students perceived stress levels too high. ${ }^{7}$ A study evaluating level of stress among postgraduate medical and dental students 
revealed 54,22 , and $10 \%$ of students with mild, moderate, and severe stress respectively. ${ }^{8}$ We can protect ourselves from the stress-induced ill-effects by knowing how the body's stress response works, its signs and symptoms, and taking appropriate steps to reduce the same. Noting the statistics of stress seen in health care profession students and due to scarcity of studies in this area, the current study was undertaken to bring about awareness of the need to care for oneself and to consume proper food or supplements routinely and especially during periods of stress, such as examinations.

Studies linking the association between psychological stress and antioxidant status have been undertaken on various body fluids. This study was undertaken to assess the total antioxidant capacity through saliva as saliva has several advantages, such as being noninvasive, cost-effective, easy to store and transport, multiple collections without much discomfort and anxiety, safer for health care providers due to reduced exposure to hepatitis $C$ virus and human immunodeficiency virus, easier to manipulate as it does not clot like blood, and so on.

The objective of the current study was to assess the total antioxidant capacity of saliva of exam-going postgraduate students studying at KLE Vishwanath Katti Institute of Dental Sciences, Belagavi, Karnataka, India, on the day of examination (stressed condition) and in the postexamination period (nonstressed condition) and correlating the results obtained with the level of stress.

\section{MATERIALS AND METHODS}

This study aimed to compare the total antioxidant capacity of saliva on the day of examination (stress condition) and in the postexamination period (nonstress condition). The trial was approved by the University's Clinical Research Ethics Board and was conducted in accordance to the consort guidelines. Recruitment, randomization, and clinical and analytical methods have been described in detail previously.,10

\section{Study Participants}

The study subjects comprised of 30 randomly selected healthy University exam answering students studying in the KLE Vishwanath Katti Institute of dental sciences, Belagavi who gave a written informed consent and were willing to participate in the study. Age of the participants was between 24-27 years. During the course of the study, all participants consumed a similar diet typical for the KLE hostels during both the "non-stress" (period post examination) and stress conditions (on the day of the examinations). They were instructed not to take any antioxidant vitamins, minerals or other such natural products, and to avoid excessive intake of fruits, vegetables, juices, wine, alcoholic drinks. There were no unintended outcomes of the measures taken.

Study participants were evaluated on the basis of the perceived stress scale (PSS) ${ }^{11}$ on both the occasions, the day of examination and in the post exam period. As expected the perceived stress scale score (PSS) obtained was higher on the day of examination than in the period post examination. Saliva samples were collected from each of the participants and labelled as group A (day of examination, stressed condition) and group B (post examination period, non-stressed condition).

\section{Saliva Collection}

On the day of collection, study participants were directed not to consume any food prior to collection of the saliva sample. Each subject was seated with their head held slightly down and was asked not to swallow or move the tongue or lips during the collection. Saliva was allowed to accumulate in their mouth for 2 minutes followed by asking them to spit the accumulated saliva into the receiving vessel. ${ }^{12}$ Similar method of collection was used on both the occasions. Saliva samples obtained were centrifuged immediately to remove cell debris $(1,000 \mathrm{~g}$ for 10 minutes at $\left.4^{\circ} \mathrm{C}\right)$. The supernatant was removed and stored in small aliquots at $4^{\circ} \mathrm{C}$ until analysis.

\section{Total Antioxidant Capacity Analysis}

The assessment of the total antioxidant capacity of saliva was done at the KLE Dr Prabhakar Kore Basic Research laboratory of KLE University, Belagavi, Karnataka, India. An aliquot of $0.1 \mathrm{~mL}$ of saliva containing a reducing agent (ethanol) was combined in an Eppendorf tube with $1 \mathrm{~mL}$ of a reagent solution, which contains $0.6 \mathrm{M}$ sulfuric acid, $28 \mathrm{mM}$ sodium phosphate, and $4 \mathrm{mM}$ ammonium molybdate. The tube was capped and incubated in thermal block at $95^{\circ} \mathrm{C}$ for 90 minutes. After the samples cooled down to room temperature, the absorbance of the aqueous solution of each was measured at $695 \mathrm{~nm}$ against a blank. Phosphomolybdenum assay is based on the reduction of phosphate-Mo (VI) to phosphate Mo (V) by the sample and subsequent formation of a bluish green color phosphate/Mo (V) complex at acid $\mathrm{pH}$. Quantitation of total antioxidant level was based on the molar absorption coefficient of the phosphomolybdenum complex. ${ }^{10}$

\section{Statistical Analysis}

Data entry was done on an excel sheet and analyzed using the Statistical Packages for the Social Sciences for Windows 19.0 (SPSS Inc. Chicago, IL, USA). The statistical comparison of the mean values obtained with respect to the two groups was evaluated using Mann-Whitney 
$\mathrm{U}$ test. The correlation between the level of stress and the total antioxidant capacity of saliva was done using Spearman's correlation test.

\section{RESULTS}

The results of the Mann-Whitney U test revealed statistically significant $(p=0.001)$ difference in the mean values of the two groups, i.e., samples obtained on the day of examination (stress condition) and in the postexamination period (nonstress condition). The total antioxidant capacity of saliva was significantly lower on the day of examination than in the postexamination period, i.e., in the stressed condition as compared with the nonstressed condition.

The results of Spearman's correlation test revealed a statistically significant ( $p=0.001, R=0.854$ ) relation between the level of stress and the total antioxidant capacity of saliva. Thus, with an increase in the level of stress, there is a decrease in the total antioxidant capacity. Through the results of the study conducted, it can be said that the total antioxidant capacity of saliva can serve as an effective marker of stress (Graphs 1 and 2).

\section{DISCUSSION}

Stress and stress-related anxiety and depression in medical and dental students are being increasingly reported in the literature. Studies have been stated earlier supporting the same. ${ }^{6-8}$ Health care education is stressful and demanding. The stress may affect the students' academic performance and mental and physical health. These studies have also found that perceived stress is associated with a lower quality of life and premature death.

Stress is not always bad. Within one's comfort zone, stress can help you compete, push you to do your best,

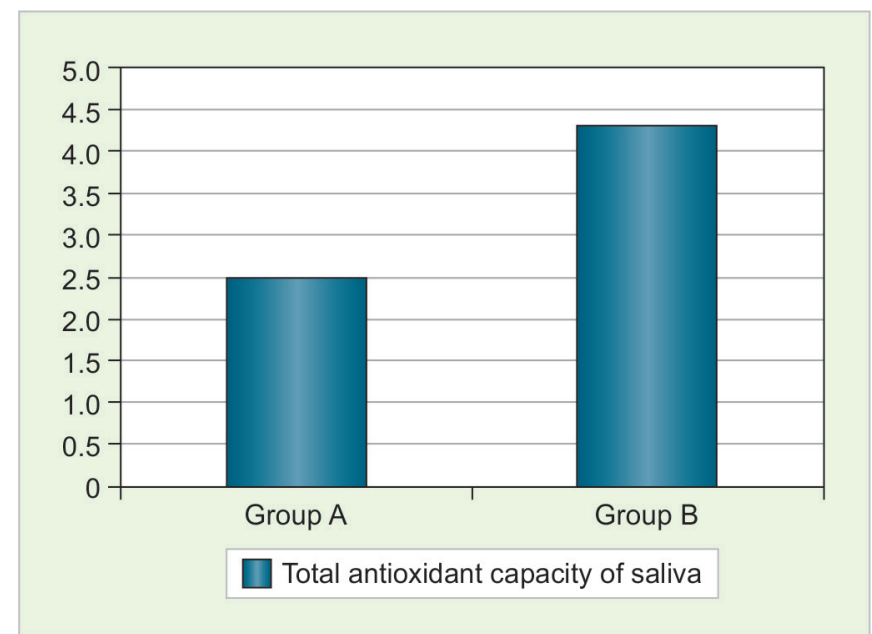

Graph 1: Total antioxidant capacity of saliva is higher in group B i.e. in samples obtained following periods of stress (post examination period) than group A, i.e., samples obtained in stressed condition (on the day of examination) even keep you secure in threatening situations. But when stress becomes overwhelming, it can damage your well-being, relationships, and quality of life. Increasing evidence exists, suggesting a link between the hypothalamic-pituitary-adrenal axis (activated during stress) and oxidative stress. The correlation between free radicles, antioxidants, organs, and organ systems is exceptionally intricate; hence, understanding the process of oxidative stress is crucial to protecting ourselves from the detrimental effects of the same.

A positive association has been found between stress and sleep disturbances, eating habits (such as eating insufficient), a lack of physical exercise, alcohol consumption, smoking, and drug consumption. ${ }^{13}$ The harmful effects of stress in the body and, in particular, oxidative stress range from asthma, obesity, diabetes, depression and anxiety, Alzheimer's disease, and so on. ${ }^{14-17}$ In the oral cavity, the effects range from periodontitis, recurrent aphthous ulcers, myofunctional pain dysfunction syndrome, atypical orofacial pain to even lichen planus, oral cancer. ${ }^{18-21}$

Lesgards et $\mathrm{al}^{22}$ studied the influence of different lifestyle factors on their test system, which measured resistance of red blood cells to oxidative challenge. Their study showed psychological stress is a major factor influencing the antioxidant status. A similar conclusion was reached by Blake-Mortimer et $\mathrm{al}^{23}$ using enzyme 5' ecto-nucleotidase (NT), a marker located on the external surface of lymphocytes. Psychology students were monitored at low level of stress (after a holiday) and at high levels of stress (examination/ thesis writing), using the profile mood score. The scores significantly coincide with the level of NT, which was higher during the stress period as compared with the nonstressed period. ${ }^{23}$

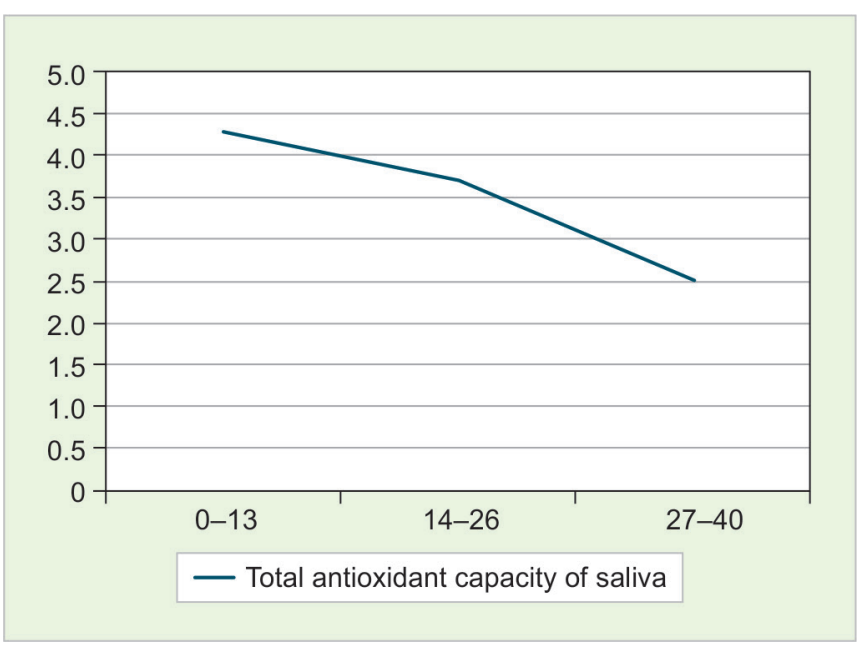

Graph 2: Negative correlation between stress and total antioxidant capacity 
The findings of the current study conducted correlate with those obtained in other studies. Sivoňová et $\mathrm{al}^{9}$ conducted a study on assessment of oxidative stress in university students during examinations. Their study was done on 15 healthy medical students in nonstressed and stressed conditions and revealed decrease in antioxidant status of plasma during periods of stress $(\mathrm{p}<0.05)$. Another study conducted by Eskiocak et $\mathrm{al}^{24}$ revealed similar results in seminal plasma. Their study was conducted on 34 medical students during periods of stress and no stress $(\mathrm{p}<0.05)$.

Møller et $\mathrm{al}^{25}$ found that psychological stress increases oxidative stress. They also suggested that regular exercise and carbohydrate-rich diet seem to increase the resistance against oxidative stress. The recommendations of studies conducted are that fruits, vegetables, and less processed staple foods, grains, and nuts ensure the best protection against the development of diseases caused by oxidative stress, such as cancer, coronary heart disease, obesity, type II diabetes, hypertension, and cataract. ${ }^{26}$ The beneficial health effect is due to antioxidants present in fruit and vegetables. ${ }^{27}$

Dietary antioxidants, such as fruits, e.g., apples, grapes, pears etc.; vegetables like beetroot, broccoli, celery etc.; and beverages, such as tea, spices, and others rich in antioxidants may have a remarkable therapeutic potential in preventing the onset of various degenerative conditions. Good nutrition especially during stressful conditions leading to oxidative stress can promote better health to prevent illnesses. The findings of the current study of a negative correlation between stress and the total antioxidant capacity indicate an important protective role of sufficient supply of antioxidants during periods of stress. Thus, supplementation with antioxidants may be beneficial routinely and especially during periods of stress.

\section{CONCLUSION}

The first step of proper stress management is awareness. We should be aware of all the existing stressors in our personal lives and develop appropriate skills to balance professional and academic demands with a healthy way of living. Most of us are responsible for majority of our own stressors and thus we should learn and pursue certain stress-decreasing practices. Developing good management skills, exercising regularly, practicing good sleeping habits are some of them.

The results of the current study suggest that total antioxidant capacity of saliva can serve as a marker of stress. The results also reveal a decrease in total antioxidant capacity during periods of stress. Supplementation of antioxidant or just consuming the right food can protect us from a wide variety of detrimental consequences of stress. Managing our stress means managing our lives. If we take charge of our stress, our lives will thank us for it.

\section{ACKNOWLEDGMENTS}

Authors would like to thank the staff of KLE Dr Prabhakar Kore Basic Research laboratory of KLE University, Belagavi have guided us with the protocol for assessment of the total antioxidant capacity of saliva especially $\mathrm{Mr}$ Shridhar C. Ghagane.Also we are grateful to Dr Supriya Vyavahare, post graduate student of Department of Public Health Dentistry of KLE Vishwanath Katti Institute of Dental Sciences who helped us with the statistical analysis of the study.

\section{REFERENCES}

1. Selye H. The evolution of the stress concept: the originator of the concept traces its development from the discovery in 1936 of the alarm reaction to modern therapeutic applications of syntoxic and catatoxic hormones. Am Sci 1973 Nov;61(6): 692-699.

2. Health Check Systems. Understanding free radicles and anti-oxidant. 2011. [cited 2016 Jul 4]. Available from: http:// www.healthchecksystems.com/antioxid.htm.

3. Pero RW, Roush GC, Markowitz MM, Miller DG. Oxidative stress, DNA repair, and cancer susceptibility. Cancer Detect Prev 1989 Dec;14(5):555-561.

4. Berg D, Youdim MB, Riederer P. Redox imbalance. Cell Tissue Res 2004 Oct 1;318(1):201-213.

5. Kohen R, Nyska A. Oxidation of biological systems: oxidative stress phenomena, antioxidants, redox reactions, and methods for their quantification. Toxicol Pathol 2002 NovDec;30(6):620-650.

6. Dahlin M, Joneborg N, Runeson B. Stress and depression among medical students: a cross-sectional study. Med Educ 2005 Jun 1;39(6):594-604.

7. El-Gilany AH, Amr M, Awadalla NJ, El-Khawaga G. Perceived stress among medical and law students in Mansoura, Egypt. Egypt J Occup Med 2009 Jan;33(1):1-3.

8. Sharma B, Prasad S, Pandey R, Singh J, Sohdi KS, Wadhwa D. Evaluation of stress among post-graduate medical and dental students: a pilot study. Delhi Psychiatry J 2013 Oct;16(2): 312-316.

9. Sivoňová M,Žitňanová I, Hlinčíková L,Škodáček I, Trebatická J, Ďuračková Z. Oxidative stress in university students during examinations. Stress 2004 Sep 1;7(3):183-188.

10. Prieto P, Pineda M, Aguilar M. Spectrophotometric quantitation of antioxidant capacity through the formation of a phosphomolybdenum complex: specific application to the determination of vitamin E. Anal Biochem 1999 May 1;269(2):337-341.

11. Cohen, S.; Williamson, GM. Perceived stress in a probability sample of the United States. In: Spacapan S, Oskamp S, editors. The social psychology of health. Newbury Park (CA): Sage; 1988. p. 31-67.

12. Navazesh M. Methods for collecting saliva. Ann N Y Acad Sci 1993 Sep 1;694(1):72-77.

13. Schneiderman N, Ironson G, Siegel SD. Stress and health: psychological, behavioral, and biological determinants. Annu Rev Clin Psychol 2005 Apr 27;1:607-628. 
14. Holguin F, Fitzpatrick A. Obesity, asthma, and oxidative stress. J Appl Physiol 2010 Mar 1;108(3):754-759.

15. Baynes JW. Role of oxidative stress in development of complications in diabetes. Diabetes 1991 Apr 1;40(4):405-412.

16. Bouayed J, Rammal H, Soulimani R. Oxidative stress and anxiety: relationship and cellular pathways. Oxid Med Cell Longev 2009 Apr-Jun;2(2):63-67.

17. Markesbery WR. Oxidative stress hypothesis in Alzheimer's disease. Free Radic Biol Med 1997 Dec 31;23(1):134-147.

18. Azizi A, Sarlati F, Parchakani A, Alirezaei S. Evaluation of whole saliva antioxidant capacity in patients with periodontal diseases. Open J Stomatol 2014 Apr 10;4:228-231.

19. Momen-Beitollahi J, Mansourian A, Momen-Heravi F, Amanlou M, Obradov S, Sahebjamee M. Assessment of salivary and serum antioxidant status in patients with recurrent aphthous stomatitis. Med Oral Patol Oral Cir Bucal 2010 Jul 1;15(4):e557-e561.

20. Ergun S, Troşala ŞC, Warnakulasuriya S, Özel S, Önal AE, Ofluoğlu D, Güven Y, Tanyeri H. Evaluation of oxidative stress and antioxidant profile in patients with oral lichen planus. J Oral Pathol Med 2011 Apr 1;40(4):286-293.

21. Bahar G, Feinmesser R, Shpitzer T, Popovtzer A, Nagler RM. Salivary analysis in oral cancer patients. Cancer 2007 Jan 1;109(1):54-59.
22. Lesgards JF, Durand P, Lassarre M, Stocker P, Lesgards G, Lanteaume A, Prost M, Lehucher-Michel MP. Assessment of lifestyle effects on the overall antioxidant capacity of healthy subjects. Environ Health Perspect 2002 May;110(5): 479-486.

23. Blake-Mortimer J, Winefield AH, Chalmers AH. Relationship between psychological stress and lymphocytic 5 '-ectonucleotidase. Int J Stress Manag 1996 Oct 1;3(4):189-207.

24. Eskiocak S, Gozen AS, Yapar SB, Tavas F, Kilic AS, Eskiocak M. Glutathione and free sulphydryl content of seminal plasma in healthy medical students during and after exam stress. Hum Reprod 2005 Sep 1;20(9):2595-2600.

25. Møller P, Wallin H, Knudsen LE. Oxidative stress associated with exercise, psychological stress and life-style factors. Chem Biol Interact 1996 Sep 27;102(1):17-36.

26. Halvorsen BL, Holte K, Myhrstad MC, Barikmo I, Hvattum E, Remberg SF, Wold AB, Haffner K, Baugerød H, Andersen LF, et al. A systematic screening of total antioxidants in dietary plants. J Nutr 2002 Mar 1;132(3):461-471.

27. Halvorsen BL, Carlsen MH, Phillips KM, Bøhn SK, Holte K, Jacobs DR Jr, Blomhoff R. Content of redox-active compounds (ie, antioxidants) in foods consumed in the United States. Am J Clin Nutr 2006 Jul 1;84(1):95-135. 